\title{
Modeling of Particle Emission During Dry Orthogonal Cutting
}

\author{
Riad Khettabi, Victor Songmene, Imed Zaghbani, and Jacques Masounave
}

(Submitted August 21, 2008; in revised form August 9, 2009)

\begin{abstract}
Because of the risks associated with exposure to metallic particles, efforts are being put into controlling and reducing them during the metal working process. Recent studies by the authors involved in this project have presented the effects of cutting speeds, workpiece material, and tool geometry on particle emission during dry machining; the authors have also proposed a new parameter, named the dust unit $\left(D_{u}\right)$, for use in evaluating the quantity of particle emissions relative to the quantity of chips produced during a machining operation. In this study, a model for predicting the particle emission (dust unit) during orthogonal turning is proposed. This model, which is based on the energy approach combined with the microfriction and the plastic deformation of the material, takes into account the tool geometry, the properties of the worked material, the cutting conditions, and the chip segmentation. The model is validated using experimental results obtained during the orthogonal turning of 6061-T6 aluminum alloy, AISI 1018, AISI 4140 steels, and grey cast iron. A good agreement was found with experimental results. This model can help in designing strategies for reducing particle emission during machining processes, at the source.
\end{abstract}

Keywords dry turning, modeling, particle emission, prediction

\section{Introduction}

Aerosols and metallic particles generated during machining processes are harmful to both operator's health and to the environment, and can also deteriorate machine-tool parts.

In general, exposure to metallic particles can cause serious pulmonary disease, as fine particles (particles with aerodynamic diameters less than $2.5 \mu \mathrm{m}$ ) can go as far as into the alveoli and into the deepest parts of the lung (Ref 1), where such exposure can generate health problems, ranging from respiratory diseases to asthma and several types of cancer. The smaller such particles are, the more they are potentially dangerous, as they can be deposited in various parts of the human system and even migrate (Ref 2, 3). Some recent findings show that such particles, also known as nanoparticles, can be as harmful as microparticles when absorbed by body cells (Ref 4). Oberdörster et al. (Ref 5) proved that some inert particles could become biologically active if their dimensions are reduced to the nanometer scale. Nanoparticles can migrate along the olfactory nerve (Ref 6) and penetrate the central neural system, eventually reaching the brain (Ref 7). Elder et al. (Ref 8) confirmed that some such particles could be found in the liver, in the kidney, and in other organs.

Ramulu et al. (Ref 9) have commented that during the drilling of Graphite-Bismaleimide Composite Material, dust generated during the machining process can affect the torque of

Riad Khettabi, Victor Songmene, Imed Zaghbani, and Jacques Masounave, ETS - Mechanical Engineering, University of Quebec, 1100 rue Notre-dame Ouest, Montreal, Quebec H3C 1K3, Canada. Contact e-mail: victor.songmene@etsmtl.ca. the cutting. The interaction between the metallic particles produced and the surface of the tool is highly detrimental to tool life and to surface integrity, and may ultimately impair the productivity of the machining equipment. In fact, during machining, the metallic particles generated can create cutting fatigue, stress localization, and shear-induced surface and subsurface micro cracks on the machining components (Ref 10). High contact stresses between the hard particle and tool faces are primarily responsible for the development of tool wear when machining metal or alloys (Ref 11). Owing to extreme conditions of pressure and temperature, the particles are trapped in the contact, and then chemical reactions occur between the three components, degrading the shape and efficiency of the cutting tool edge as well as the surface quality and dimensional accuracy of the finished product (Ref 12, 13). Hwang et al. (Ref 14) observed significant rises in friction coefficient and cutting force after a particle migrates to the sliding interface. The shape and size of the metallic particle trapped at the interface also influence the wear mechanism, and an increase in particle angularity results in a significant increase in abrasive or erosive wear rates (Ref 15-17). Stachowiak and Stachowiak (Ref 18) concluded that rounded particles generate round craters and smooth grooves while angular particles produce sharp indents and narrow cutting grooves on the contacting surface.

In 1999, a World Health Organization working committee on airborne particles pointed out the need for research into particle generation during the manufacturing process, to allow regulations and controls to be brought in with respect to the production of airborne particles (Ref 19). Tönshoff et al. (Ref 20) showed that during grinding, most metallic dust generated is breathable, and, that without a dust suction system in place, the level of dust particle concentration in the air becomes higher than the threshold set under the NAOSH (North American Occupation Safety and Health) regulations.

Most machine tools are not equipped with particle removal systems, and it is more difficult to find solutions for capturing 
or removing particles, especially nanometric particles, from the working area than to reduce particle emissions at the source. While it has been confirmed that the use of cutting fluids can reduce particle formation by $\sim 40-50 \%$ ( $\operatorname{Ref} 21$ ), cutting fluids are, however, costly (initial purchase and treatment of used fluids) and are sources of bacterial contaminations (Ref 22, 23). Indeed, exposure to metalworking fluids has been associated with respiratory problems and skin disorders (Ref 24, 25). Other studies (Ref 26, 27) have shown that wet machining generates more aerosols than dry machining. In fact, wet aerosols are made of cutting fluid mist and metallic particles, and dry machining is, therefore, preferred over wet machining. In addition, dry cutting helps promote chip recycling.

In order to limit and eliminate the danger at the source, it is necessary not only to understand how particles are formed, but also to be able to predict their emission. Experimental studies have shown that dry aerosols generated during metal machining depend on the workpiece material and its conditions, as well as on the cutting parameters (Ref 21, 28, 29) and the tool geometry (Ref 30, 31) used.

The predictive modeling of metallic particle emission is required in finding strategies to reduce such emissions at the source while remaining competitive. To the authors' knowledge, the literature contains only limited models for predicting particle emissions during machining processes (Ref 27, 30, 31). Zipf and Bieniawski (Ref 32) proposed a phenomenological interpretation for fine particle emission, but only during coal machining, thus making it inapplicable to metals. That is also the case for the semi-empirical model developed by Page and Organiscak (Ref 33) for the airborne respirable particle concentrations in coal mine drilling.

For metallic particles generated during machining processes, cutting conditions (cutting speed, depth of cut, and feed rate), tool geometry (rake angle and lead angle), and workpiece material, have been found to be influential factors (Ref 30, 31). They also have an impact on the cutting process itself, especially on the shearing of metal, on the friction, and on the plastic deformation.

Friction and plastic deformation are believed to be major sources of particle emissions in machining. Plastic deformation affects the chip formation mode, and the creation of new surfaces, cracks, and crack propagation depend on the behavior of the workpiece material. High ductile deformation, which is generalized in the mass of the chip, causes friction in the shear planes, producing a high number of particles. Friction can thus cause particle detachment by various means.

Many researchers have studied particle generation by friction, using the characterization of the total quantity of particles produced (Ref 34-36). Their results and the models they have proposed become limited and impractical when the particle size is micrometric or sub-micrometric. Ko et al. (Ref 37) modeled the phenomenon of frictional particle production between two surfaces assuming that surface asperities' shapes are randomly spaced cylindrical corrugations. Their study showed the effect of surface roughness on particle emission. Akarca et al. (Ref 38) found that during the sliding wear of the A356 aluminum alloy, wear particles are generated by the nucleation of voids and the propagation of micro-cracks at a certain depth under the surface. Hsu-Wei Fang (Ref 39, 40) proposed a special surface texture design to control surface asperities to identify the mechanism of particle detachment by friction, and proposed a predictive mathematical model.
However, Hsu-Wei Fang's model (Ref 39, 40) uses dimensions for the surface texture that are not realistic since the shape and the distribution of surface asperities of most mechanical parts are random. During the cutting process, the friction at the toolchip interface and at the tool workpiece interface can both produce particles.

Rautio et al. (Ref 41) developed an empirical model for particle emission. They compared the quantity of particle generated to the quantity of chip removed from the workpiece, and found that this fraction is inversely proportional to the chip thickness. They then concluded that the fraction of particle generated is proportional to the ratio of the cutting speed to the feed rate used. While simple and very convenient, this model was, however, validated only on medium-density fiberboard materials. Further, it fails to recognize the behavior of ductile materials on particles emission, which presents a decreasing zone beyond a certain cutting speed (Ref 21, 27-31).

Recent experimental studies performed by Khettabi et al. (Ref 30, 31) showed the major effects of different cutting parameters, tool geometries, and workpiece materials on metallic particle generation during the machining of metallic materials. Zaghbani et al. (Ref 27) proposed a semi-predictive model for fine metallic particle generation during high-speed milling using the energy created in the primary chip deformation zone and the measured cutting forces data. The model, which depends mostly on the cutting speed used, was validated only on the 6061-T6 aluminum alloy. Friction and deformation at the tool-chip interface, which influence chip formation, can also influence the generation of metallic particles, as can material properties.

In this study, a fully predictive model is developed for metallic particle emission during orthogonal cutting. The model is based on phenomenological aspects: energy approach combined with the friction and the plastic deformation of the material. It includes cutting parameters, material properties, temperature, shear stress, shear stress rate, force, and the chip flow localization parameter developed by Xie et al. (Ref 42). The predictive force-temperature model developed by Zaghbani and Songmene for the high speed milling of ductile materials (Ref 43) is transformed in this study into a predictive model for orthogonal cutting, and is used to estimate the energy involved in the cutting process. The metallic particle emission estimated in this study represents the dust unit $\left(D_{\mathrm{u}}\right)$ (Ref 30) which represents the fraction of material removed that is in fine or ultrafine particle form. The materials tested were aluminum alloy 6061-T6, steels (AISI 1018 \& AISI 4140) and grey cast iron. The model is validated using experimental test results presented in a recent study (Ref 31 ), and its sensitivity to cutting conditions allows us to locate the dangerous zones corresponding to the conditions under which particle emission is at a maximum.

\section{Particle Emission Modeling}

Particle emission mechanisms during metal cutting were identified. The model proposed in this work is based on different aspects, including the tool geometry, the workpiece material properties, the cutting conditions, and chip segmentation. In addition, the modeling uses the energy approach, combined with the microfriction and the plastic deformation of the material. 
The modeling was based on analytical development and experimental data. The materials tested were aluminum alloy 6061-T6, steels (AISI 1018 \& AISI 4140), and grey cast iron. The experimental parameters used for orthogonal cutting are summarized in Table 1. The cutting operation took place in a box (particle recovery enclosure) to facilitate the collection of particles generated. The measurement was performed using two instruments (particle scanning mobility particle sizer "SMPS" and aerosol particle sizer "APS"), connected to a particle recovery enclosure by a suction pipe. The acquisition system was connected in order to help in the analysis.

\subsection{Mechanisms of Particle Production}

The formation of fine particles during the cutting process is caused by different phenomena, including macroscopic and microscopic friction, plastic deformation, and chip formation mode. As the chip micro-segments rub against each other, they produce micrometric and nanometric size particles. Similarly, the friction at the rake face between chip and tool also produces particles.

Information on particle emission mechanisms can be obtained through the analysis of chips. Figure 1 illustrates the mechanisms of particle emission caused by friction of the chip on the tool rake face. Particle formation by friction proceeds through two main steps, depending on the workpiece material. Step 1 occurs when the material is separated, while Step 2 takes place when the chip slides on the tool rake face. In the case of brittle materials, the chip is formed by brittle fracture, with the

Table 1 Conditions and parameters used during the test

\begin{tabular}{ll}
\hline Operation & Orthogonal cutting \\
Feed rate, $\mathrm{mm} / \mathrm{rev}$ & 0.203 \\
Cutting speed, $\mathrm{m} / \mathrm{min}$ & $0-300$ \\
Tool material & Uncoated carbide \\
Rake angles, degrees & $-7,0,+7$ \\
Lubricant \& coolant & None \\
Workpiece materials & Aluminium alloy 6061-T6 \\
& AISI 1018 steel cold-rolled \\
& AISI 4140 steel quenched \\
& and tempered \\
& Grey cast iron \\
\hline
\end{tabular}

chip contact length being very small. In that situation, the contact between the tool material and the irregular chip surface can break up particles from the internal chip surface. If the workpiece material is ductile, then the chip will be formed by micro-segments that undergo a local work hardening due to the action of some asperities of the tool rake face, after which the hardened small part is separated by a local brittle fracture. This mechanism describes how friction or microfriction can produce small particles during machining. The size of the particles separated depends on the tool rake face roughness, the cutting conditions, and the workpiece material.

The temperature during the cutting process can alter the mechanical properties of the material, and modify the chip formation mode and the particle emission. The temperature and the plastic deformation effects are integrated into the deformation energy that will be used later in modeling.

\subsection{Empirical Modeling of the Effect of Cutting Speed on Particle Emission}

Air quality is usually assessed using particle concentration, and in most measuring instruments; the assessment is done by counting the number of particles going through the measuring device while the air is sucked in at a known flow rate, and by calculating the concentration $\left(\mathrm{mg} / \mathrm{m}^{3}\right)$ using the material's density, and assuming a spherical shape for the particles.

In the case of machining processes, several authors (Ref 30, $44,45)$ have proposed the use of a metric related to chip removal or to the amount of chip removed from the part shape being machined.

Arumugan et al. (Ref 46) introduced a "Green factor," defined as the ratio of the metal removal rate $\left(\mathrm{m}^{3} / \mathrm{min}\right)$ to the aerosol mass concentration $\left(\mathrm{mg} / \mathrm{m}^{3}\right)$. The higher the green factor, the lower the concentration of the particles generated and the more benign the overall process. This factor has a misrepresentative dimension $\left(\mathrm{m}^{6} \mathrm{~min}^{-1} \mathrm{mg}^{-1}\right)$.

Palmqvist and Gustafsson (Ref 45) proposed and used a dust unit which indicates the amount of dust produced per unit volume of wood removed during planning and milling operations. Their models had two processing parameters (feed and depth of cut) while the machining process usually involved several cutting parameters. Moreover, the unit used could be misleading since particle emission is evaluated in mass and compared to a volume of materials removed.

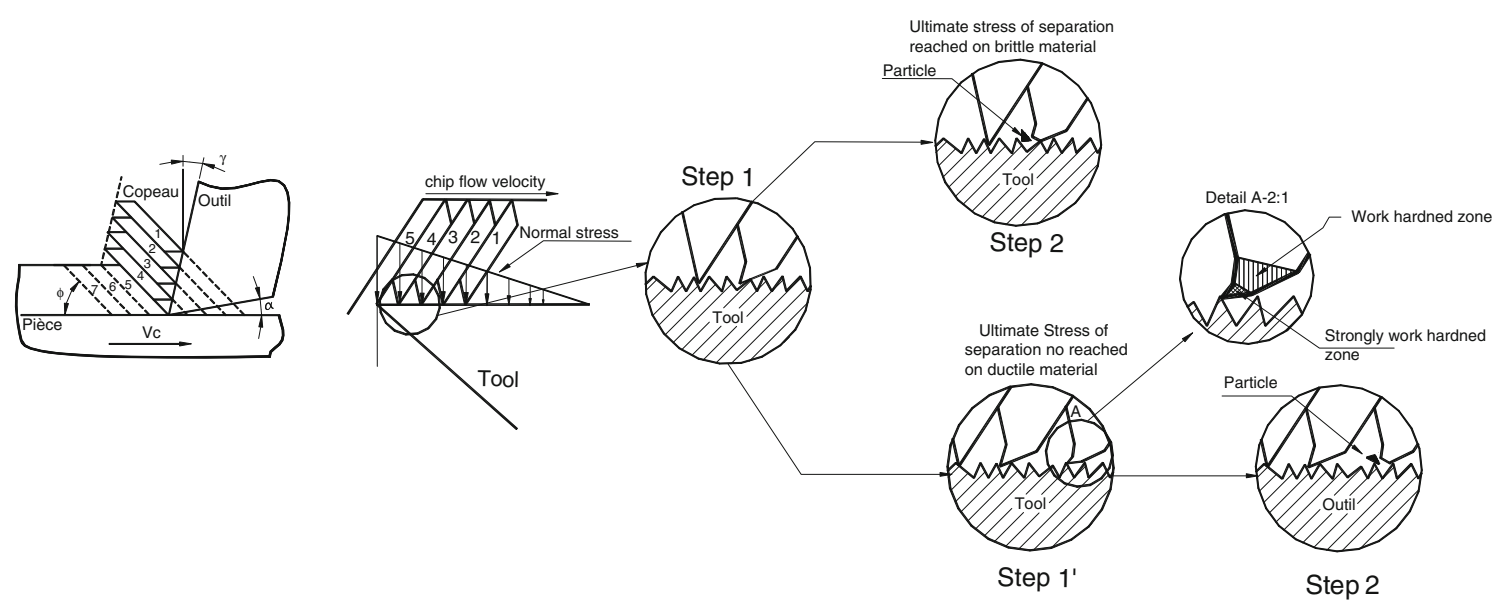

Fig. 1 Schematic illustration of mechanisms of dust emission at the chip-tool 
Khettabi et al. (Ref 30) proposed a new dimensionless index, named the dust unit $\left(D_{\mathrm{u}}\right)$, and defined as the ratio of the dust mass to the quantity of chip removed from the workpiece material, knowing that metal cutting is aimed at removing chips to produce a desired part shape.

$D_{\mathrm{u}}=\frac{m_{\text {Dust }}}{m_{\text {Chip }}}$

where $m_{\text {Dust }}(\mathrm{g})$ is the mass of total dust sampled computed from the particle concentration as described in Khettabi et al. (Ref 30) and $m_{\text {Chip }}(\mathrm{g})$ is the mass of the chip produced.

The Khettabi dust unit $\left(D_{\mathrm{u}}\right)$ can be interpreted as the fraction of the material removed from the workpiece that is in fine or ultrafine particle form as compared to the total quantity of chips. Rautio et al. (Ref 41) also used a similar dimensionless index to study particle emission during the milling of mediumdensity fiberboard materials, as did Zaghbani et al. (Ref 27) in their study on particle emission when milling an aluminum alloy. Khettabi et al. (Ref 30) also developed an experimental particle emission model relating the dust unit $\left(D_{\mathrm{u}}\right)$ to the cutting speed, and described by the following relationship:

$D_{\mathrm{u}}=\frac{b}{V^{c} \exp (a / V)}$

where $D_{\mathrm{u}}$ (dimensionless) is the dust unit, defined as the ratio of the particle mass to the chip mass removed; $V(\mathrm{~m} / \mathrm{min})$ the cutting speed; and $a, b$, and $c$ are constants dependent on the workpiece material and the tool geometry.

The proposed model fits the experimental data very well, as shown in Fig. 2. However, it is necessary to have a predictive model to find efficient strategies for limiting particle emissions at the source, and to that end, an analytical model is developed and validated.

\subsection{Analytical Modeling of Particle Emission}

Particle emission modeling can be based on the energy approach, combined with macroscopic friction (tool-chip), microfriction, and plastic deformation of materials. The energy provided by the tool must be higher than the extraction energy required for a particle to leave the parent material. This condition is similar to a common phenomenon known in physics and chemistry: to activate any reaction, it is necessary to provide enough energy to the system to break the bonds to form the corpuscle. The quantity of these particles follows an exponential law (Ref 47). In this study, the following form was proposed to calculate the quantity of particles produced during machining:

$D_{\mathrm{u}} \propto e^{-\left(E_{\mathrm{A}} / E\right)}$

where $E$ is the cutting energy per unit surface cut and per unit time $\left(\mathrm{W} / \mathrm{mm}^{2} \mathrm{~s}\right)$, and $E_{\mathrm{A}}$ is the energy state of the particle (particle activation energy per unit surface per unit time, $\mathrm{W} / \mathrm{mm}^{2} \mathrm{~s}$ ). It is assumed that particles of the same size that are detached from the same zone find themselves in the same energy state. The other term, $E_{\mathrm{A}}$, depends on the size of the particle, on the emission zone, and especially, on the material being machined.

The effect of friction on the particle emission at the tool-chip interface is influenced by two main parameters: the chip segmentation density $\eta_{\mathrm{S}}$ and the roughness of the face of cut of the tool $R_{\mathrm{a}}$. The chip friction on the rake face and the cutting
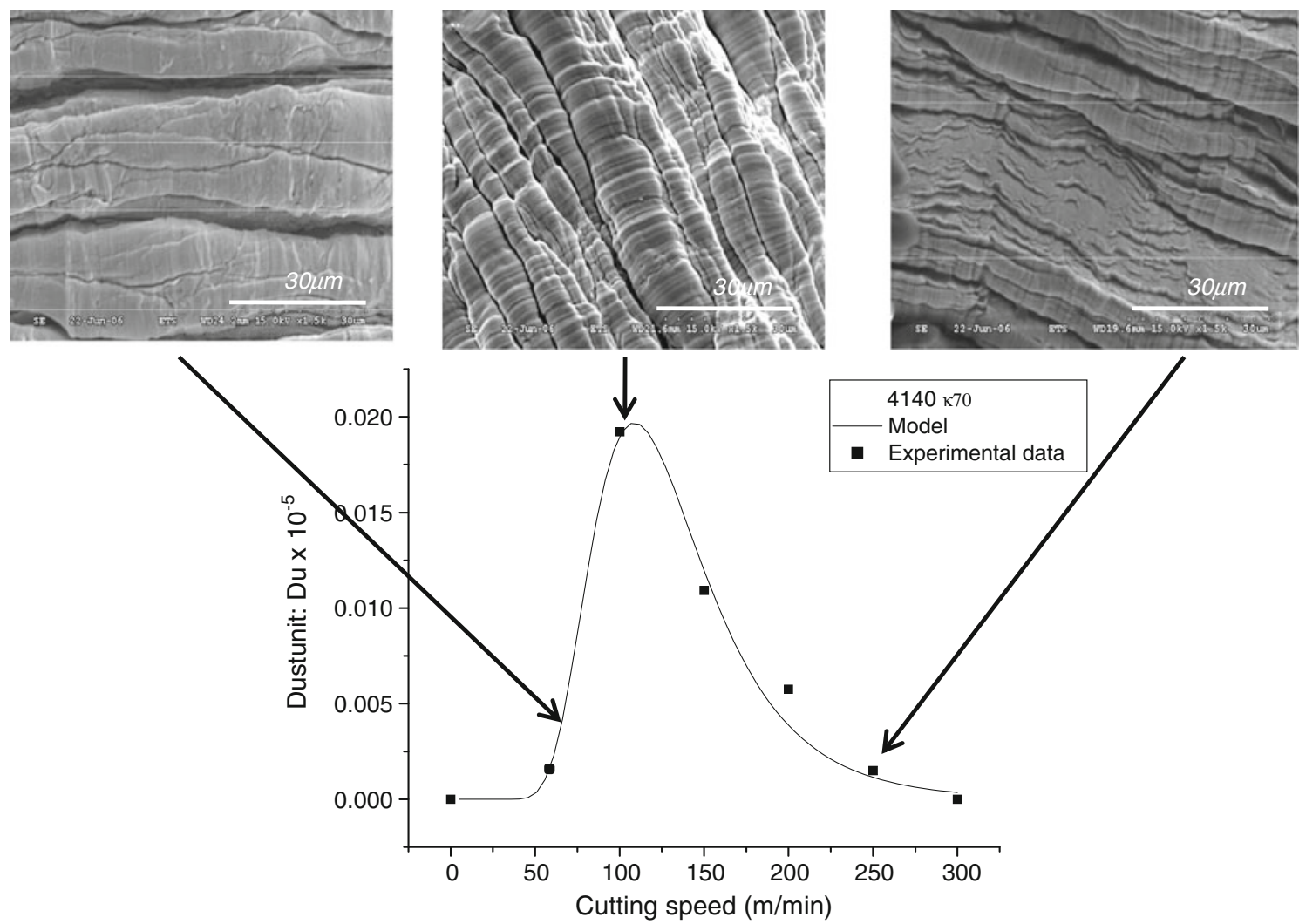

Fig. 2 Predicted dust emission data as given by Eq 1 (line) compared to experimental data (solid points) (Ref 30) 
forces can be reduced when the roughness is minimized, which consequently increases the tool life and facilitates chip evacuation. Therefore, minimizing the roughness can be beneficial for reducing particle emissions. Arumugam et al. (Ref 44, 46) tested the PCD (physical vapor deposition) tools, the unpolished CVD (chemical vapor deposition) tools, and the polished CVD tools, and found that polished CVD tools produce fewer particles than PCD and unpolished CVD tools (Ref 44, 46). Under these conditions, according to the frictionrelated mechanisms of particle emission described in Fig. 1, the following proportionality can be considered:

$D_{\mathrm{u}} \propto R_{\mathrm{a}} \times \eta_{\mathrm{S}}$

The chip segmentation was already defined by Xie et al. (Ref 42) using a chip segmentation coefficient $\beta$ :

$\beta=-\frac{\sqrt{3}}{m}\left[\mu+\frac{0.9 \frac{\partial \tau}{\partial T}}{\rho_{p} C_{p}\left(1+1.328 B_{0}\right)}\right]\left[\mu \gamma+1-\frac{0.664 B_{0}}{1+1.328 B_{0}}\right]$

where $T$ is the temperature, $\rho$ is workpiece density $\left(\mathrm{kg} / \mathrm{m}^{3}\right)$, $C_{p}$ is workpiece-specific heat $(\mathrm{J} / \mathrm{kg} \mathrm{K}), \mu$ is the strain hardening parameter, $m$ is the strain rate sensitivity, $\tau$ is the shear stress, and $B_{0}$ is a coefficient, defined as follows:

$B_{0}=\sqrt{\frac{K_{p} \gamma_{\mathrm{AB}}}{V f}}$

Here, $K_{p}$ is the workpiece thermal conductivity $(\mathrm{W} / \mathrm{m})$, and $\gamma_{\mathrm{AB}}$ is the shear in the primary shear zone.

There is a critical value $\left(\beta_{\mathrm{c}}\right)$ for which the chip becomes segmented. This coefficient $\beta$ has a maximum value $\left(\beta_{\max }\right)$ which depends on the process, material, and the cutting conditions. Xie et al. (Ref 42) found that steels have a critical coefficient of around 5 for the tested cutting condition. For aluminum alloys (Fig. 3), it was found, under the experimental conditions, that the critical value $\left(\beta_{c}\right)$ is approximately 6.2 , and that the maximum value of the flow localization parameter is similar to that of steels. For grey cast iron, there is no continuous chip, and the value of $\left(\beta_{c}\right)$ is close to that of $\left(\beta_{\max }\right)$. The method used to calculate the flow localization parameter is detailed in Appendix B.

Taking into account Eq 4, 5, and 6, the friction effect at the tool-chip interface can be estimated as

$D_{\mathrm{u}} \propto \frac{\beta_{\max }-\beta}{\beta_{\mathrm{c}}} \times R_{\mathrm{a}} \times \eta_{\mathrm{S}}$

In addition, particle emission is significantly influenced by material properties, including its toughness: tougher materials produce more particles during machining than do brittle materials ( $\operatorname{Ref} 21,28,29)$. An increase in the cutting speed is accompanied by an increase in temperature in the cutting zone. Initially, the increase in the cutting speed improves the mechanical properties, but beyond some values, the mechanical properties start to decrease. When the speed is increased, the temperature increases as well, after which the mechanical properties fall when a certain temperature (or critical speed) is reached. This situation only applies in the case of ductile materials. Brittle materials for their part cannot be softened, but their yield strengths can be improved, which is why the particle emission rate always increases with the cutting speed. This behavior is schematized in Fig. 4, and is in agreement with the
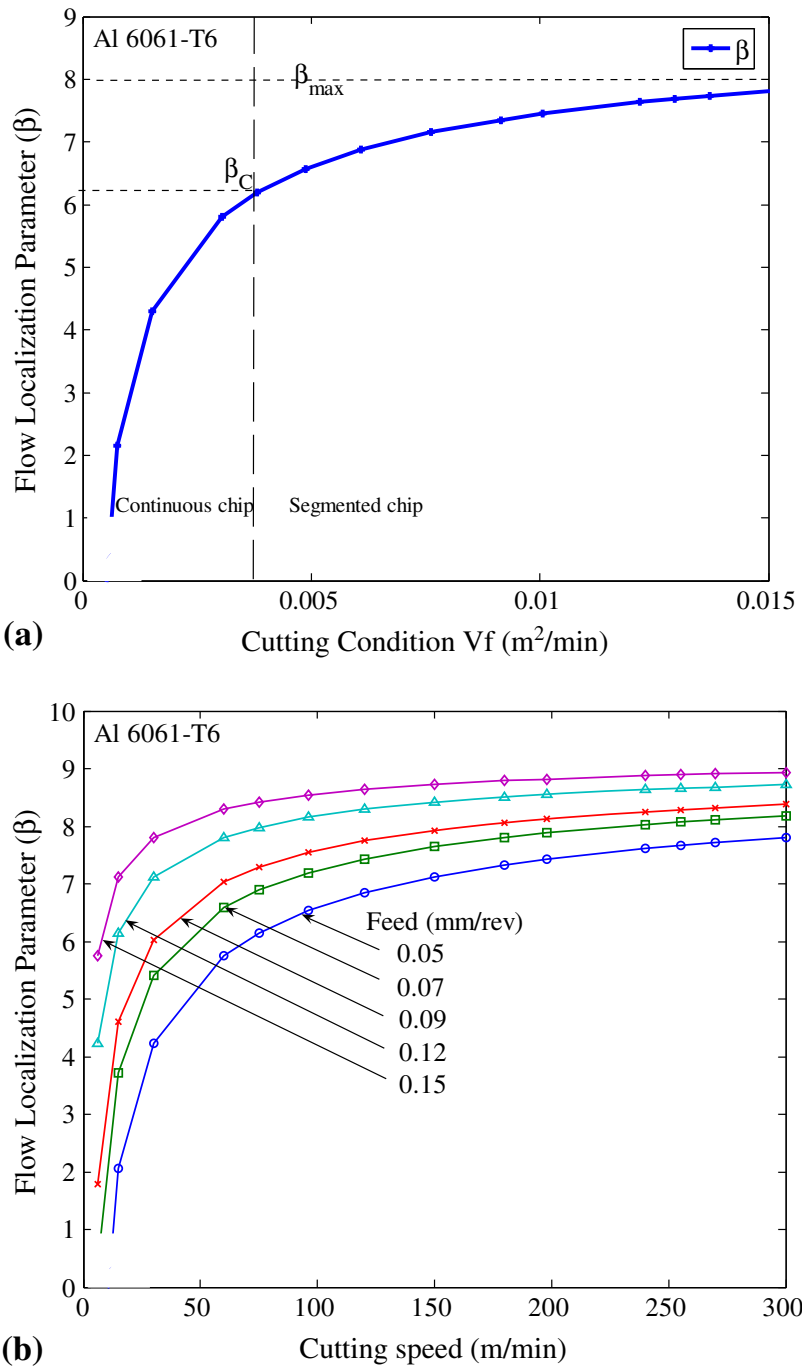

Fig. 3 Flow localization parameter for aluminum alloy 6061-T6: (a) as function of $V f$, (b) as function of cutting speed and for different feeds

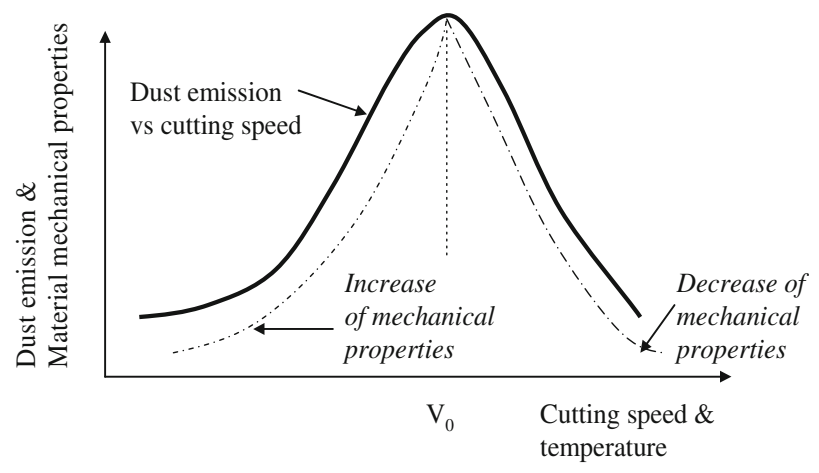

Fig. 4 Cutting speed effect on mechanical behavior and dust emission

experimental data presented in Fig. 2 and 5-9. Therefore, it can be formulated that:

$D_{\mathrm{u}} \propto f\left(\frac{V_{0}}{V}\right)$ 
Particle production is also a phenomenon related to the material plasticity and the chip formation mode. An increase in the cutting speed is accompanied by an increase in the temperature in the primary and secondary shear zones. The effect of the cutting speed is characterized by a competition of two phenomena (Fig. 2, 4, and 6-15): the friction in the chip shearing zone, which produces a lot of particles; and the high

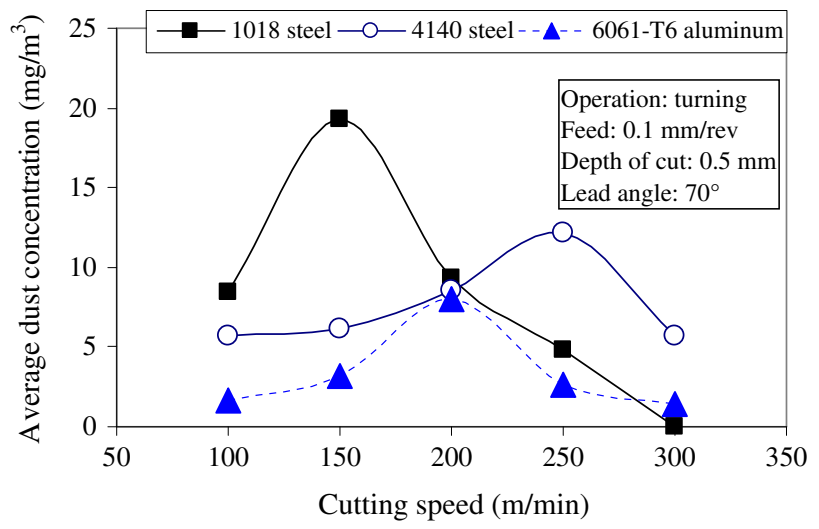

Fig. 5 Average dust concentration (PM2.5) as a function of cutting speed when turning steels and 6061-T6 aluminum ductile deformation, taking place in the chip. The friction produces particles only when the chip slip planes undergo a strong movement. Maximum particle generation is due mainly to this type of movement on the one hand, and to the high density of the shearing planes, on the other. At very low speeds, the chip crack is controlled by its brittleness (Fig. 6-9). Because the crack opens, there is neither contact nor friction between its lips. At intermediate speeds, the slip planes are localized, and their density increases, as does the friction between the lips (Ref 48). In this situation, the plastic deformation is limited, and located in the shear plane (Fig. 6-9). Shear rates are, therefore, considered very important, and help in the particle detachment process. At very high speeds, the density of segmentation is lower, and the plastic deformation is delocalized; consequently, the generation of fine particle tends to decrease, as noted by Zaghbani et al. (Ref 27) during the machining of 6061-T6 aluminum alloy at cutting speeds ranging from 300 to $900 \mathrm{~m} / \mathrm{min}$. If the lips of the crack open, which is the case with intrinsically fragile materials, there is no friction, and thus the quantity of fine emitted particles is negligible.

A suitable model should take into account the above mentioned phenomena (Eq 3-7). The correlation between different parameters is convoluted. Since the cutting phenomenon is a continuous process, the energy aspect and the cutting speed effect are not independent, as the cutting energy depends on the cutting speed. Furthermore, the cutting speed

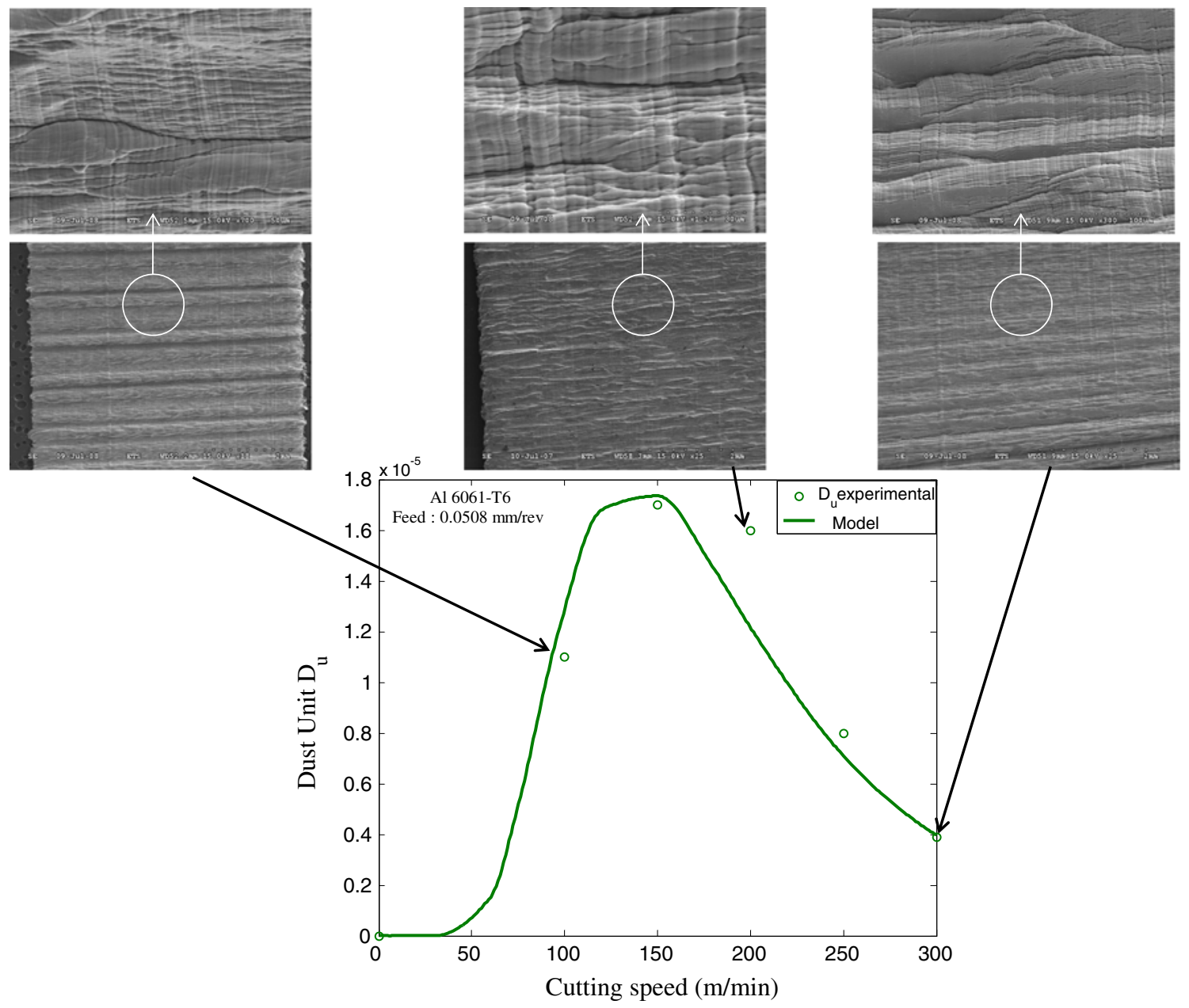

Fig. 6 Simulation results and experimental results for dust emission during dry machining of Al 6061-T6 


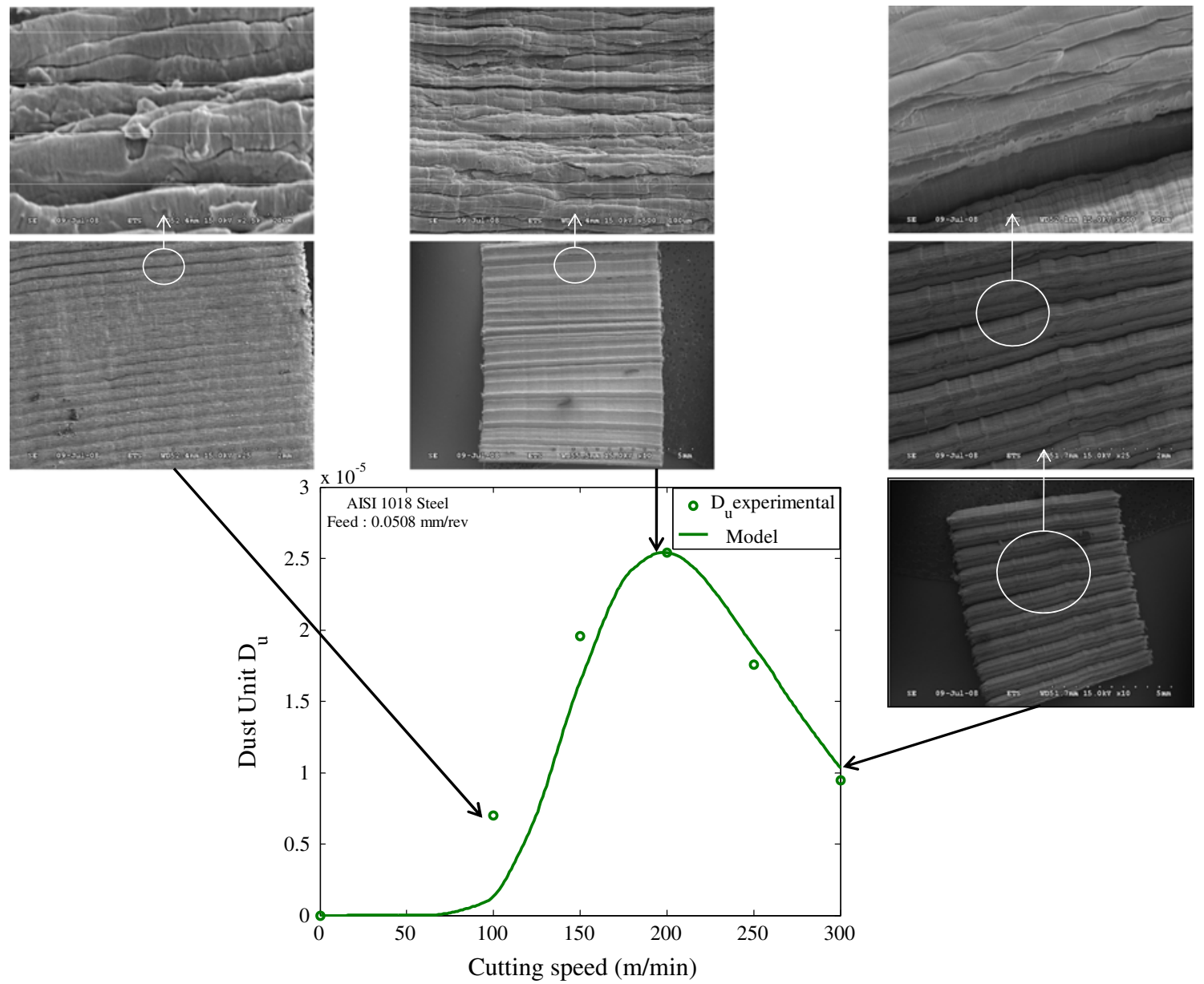

Fig. 7 Simulation results and experimental results for dust emission during dry machining of AISI 1018 steel

significantly influences the material behavior and the chip formation mode. Consequently, a multiplicative form is adopted to develop a general model. The expected dependency can be written as follows:

$$
\begin{aligned}
D_{\mathrm{u}}= & A \times \frac{\beta_{\mathrm{max}}-\beta}{\beta_{\mathrm{c}}} \times R_{\mathrm{a}} \times \eta_{S} \cdot\left(\frac{V_{0}}{V}\right)^{\delta} \\
& \times \exp \left(\frac{-E_{\mathrm{A}}}{\tan \phi\left(1-C_{\mathrm{h}} \sin \alpha\right) V_{\mathrm{c}} \frac{F_{\mathrm{sh}}}{b f}}\right)
\end{aligned}
$$

where $A$ is the factor of proportionality, and $\delta$ is a material parameter introduced to characterize the ability of the material to produce metallic particles. For each material, a constant, $\delta$, is attributed. The parameter, $\delta$, is experimentally determined to obey the following criteria (Eq 10):

$\delta \equiv\left\{\begin{array}{l}\delta \geq 1 \rightarrow \text { Ductile materials } \\ 0.5<\delta<1 \rightarrow \text { Semi-ductile materials } \\ 0<\delta \leq 0.5 \rightarrow \text { Britlle materials }\end{array}\right.$

All parameters in Eq 9, such as the rake angle $\alpha$, the shear angle $\phi$, the cutting speed $V$, the feed $f$, the roughness $R_{\mathrm{a}}, \beta_{\max }$, and $\beta_{\mathrm{c}}$, can be known or easily determined. The shearing force and temperature can be measured directly or estimated, although measurements will be difficult for a few processes. Estimation is possible using the Needelman-Lemonds constitutive equations. The procedure used in estimating $D_{\mathrm{u}}$ for a given set of cutting conditions is illustrated by the flowchart in Fig. 16.

This global model (Eq 9) was verified using a tool geometry variation. The experimental data on steels and aluminum alloys presented in Ref 31 show good agreement with the model within the experimental conditions (Fig. 17). The experimental tests were repeated twice.

\section{Model Validation, Results, and Discussion}

The predictive particle emission model (Eq 9) is found to be in agreement with experimental results. The proposed algorithm (Appendix A) was programmed, and then used to simulate particle emissions during the dry turning of aluminum 6061-T6, AISI 1018, and 4140 steels. The cutting speed was varied from 100 to $300 \mathrm{~m} / \mathrm{min}$, and the feed was kept constant at $0.0508 \mathrm{~mm} /$ rev for all the tests. Carbide tools with different rake angles $\left(-7^{\circ}\right.$, $0^{\circ}$, and $7^{\circ}$ ) were also used for all the tests. The material constitutive equation parameters were obtained from the literature, and it was proven that the average values for the strain, strain rate, and the temperature are not very sensitive to cutting conditions (Ref 49). The simulated results were compared with experimental results, and a good agreement was found (Ref 31$)$.

The coefficient, $A$, in Eq 9 is the adjustment factor of proportionality, and depends on the material and on the process. 


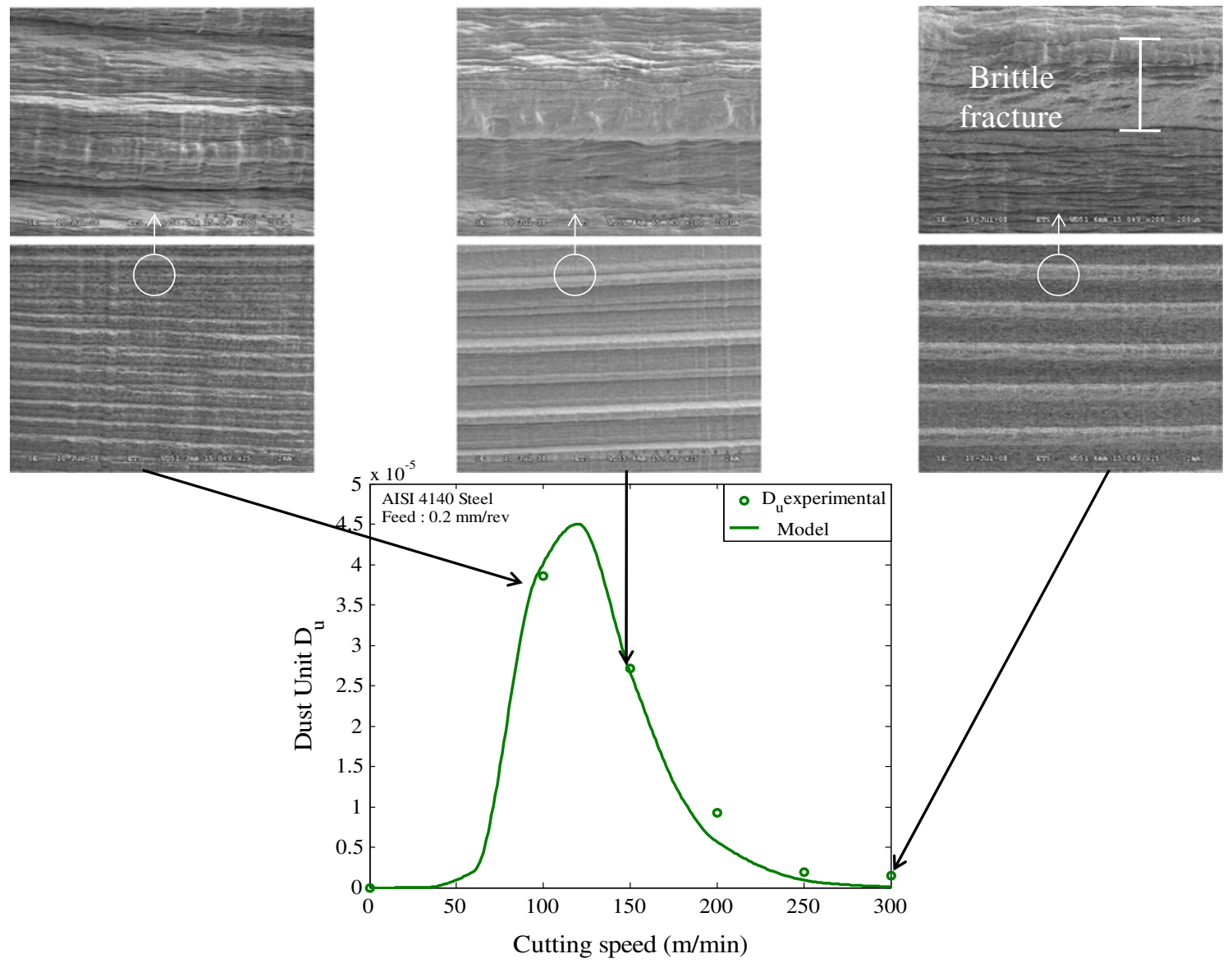

Fig. 8 Simulation results and experimental results for dust emission during dry machining of AISI 4140 steel

The chip segmentation or brittleness is characterized by the effect of the flow localization parameter $\frac{\beta_{\max }-\beta}{\beta_{\mathrm{c}}} \times R_{\mathrm{a}} \times \eta_{\mathrm{S}}$. With brittle materials, there is no continuous chip, and $\beta_{\mathrm{c}}$ is close to $\beta_{\max }$, and as a result, this term becomes very small. The flow localization parameter is plotted (such as Fig. $3 a$ and $b$ ) using Eq 4. The $\beta_{\max }$ is identified directly from the graph, and $\beta_{\mathrm{c}}$ (set after analyzing the chip formed) is the value at which the chip becomes segmented.

The parameter, $\delta$, is set experimentally to respect the condition (Eq 10), and the activation energy is affected by the microstructure of the workpiece material and the particle size. The microporosity in certain materials plays an important role in the characterization of the activation energy.

The model identification results for the orthogonal cutting of 6061-T6 aluminum alloy, 4140 steel, 1018 steel, and grey cast iron are presented in Table 2 . The particle activation energy, $E_{a}$, for aluminum alloy is lower than that for steels, meaning that fine and ultrafine particles can detach more easily from aluminum alloy than from steels. It also means that the aluminum alloy can be heated easily to facilitate the separation. In this situation, just a little energy is required to detach a particle from the parent material.

\subsection{Effect of the Cutting Speed}

Figures 9-12 illustrate particle generation as a function of cutting speeds for different materials. The experimental data present a good agreement with the model because it includes the cutting condition and workpiece material parameters. In general, a small difference is observed, and can be attributed to the measurement accuracy or to the formation of a built-up edge during the cutting process.

\subsection{Combined Effect of the Cutting Speed and the Rake Angle}

Figures 10-12 present the simulation results for particle emission as a function of the tool rake angles and the cutting speeds for aluminum alloy 6061-T6, AISI 1018, 4140 steels, and grey cast iron. These results show good agreement with experimental data and the proposed model results (Fig. 17). Even nanoparticle emission results during machining confirm the rake angle effect (Ref 31$)$ : when the tool rake angle increases, the particle emission also increases.

\subsection{Combined Effect of the Feed and the Cutting Speed}

Figures 13-15 present the simulation results for particle emission as a function of the feed and cutting speed for the dry machining of aluminum alloy 6061-T6, AISI 1018, and AISI 4140 steels. It was found that the generated particle decreases with chip thickness, a result which is consistent with the experimental findings of Ref 40 and 45 . Therefore, an increase in the feed rate reduces the amount of particles generated during machining. When the feed rate and cutting speeds both increase, the chip becomes more segmented, and consequently, the particle emission decreases. 

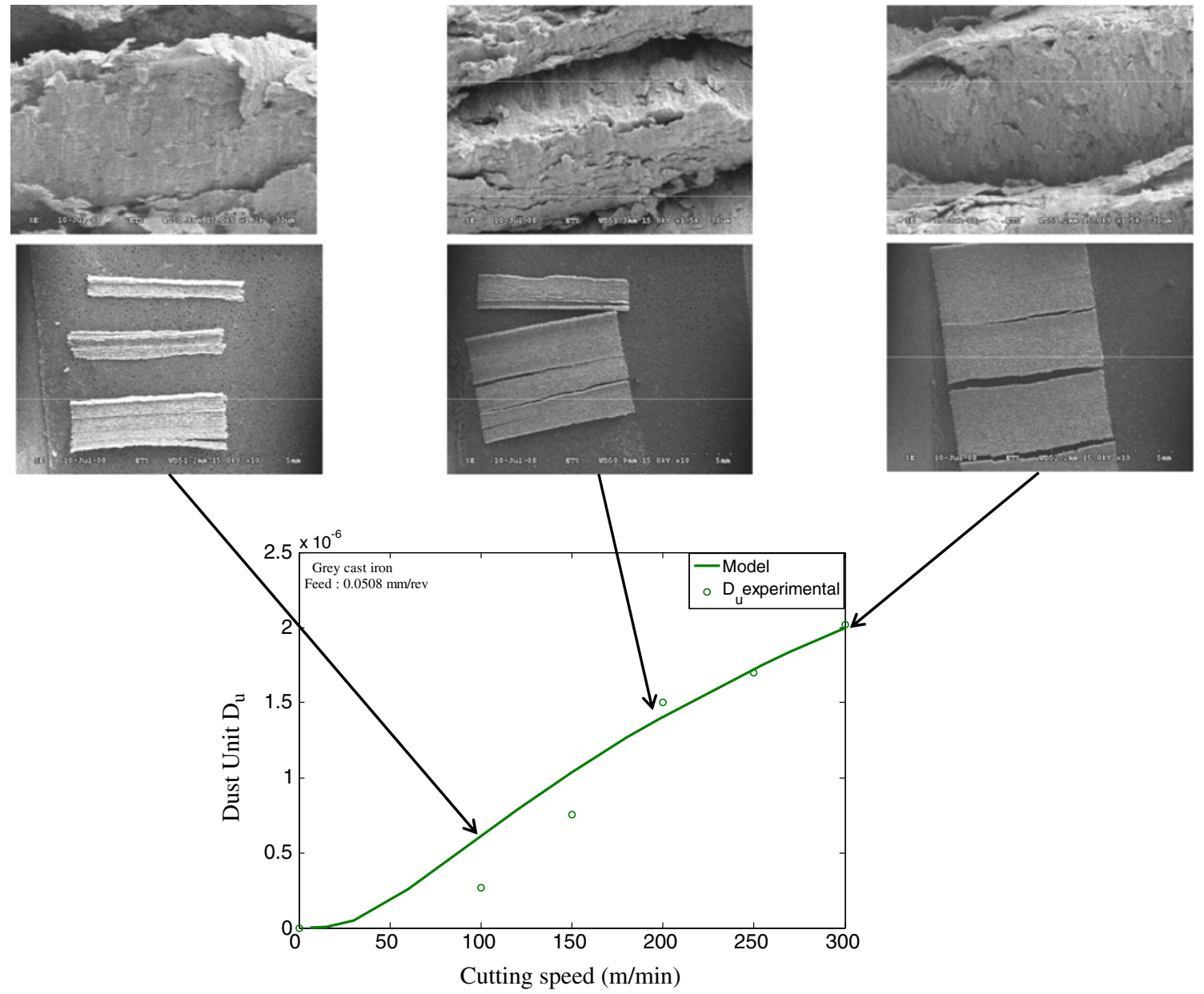

Fig. 9 Simulation results and experimental results for dust emission during dry machining of grey cast iron

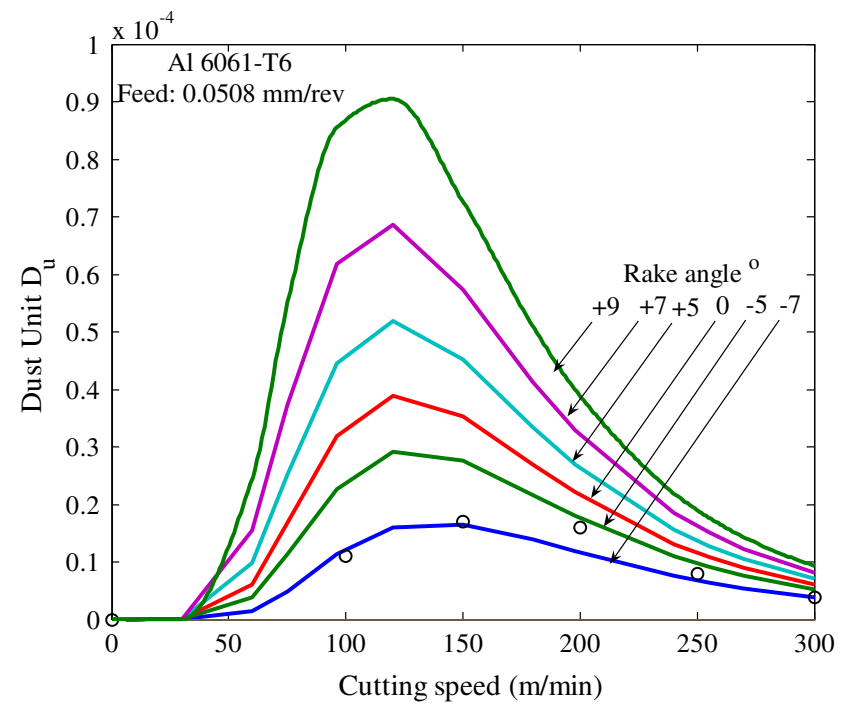

Fig. 10 Simulation results for dust emission varying on rake angle and cutting speed during dry machining of Al 6061-T6

\section{Conclusions}

A predictive particle emission model was proposed in this study. A phenomenological description was developed and

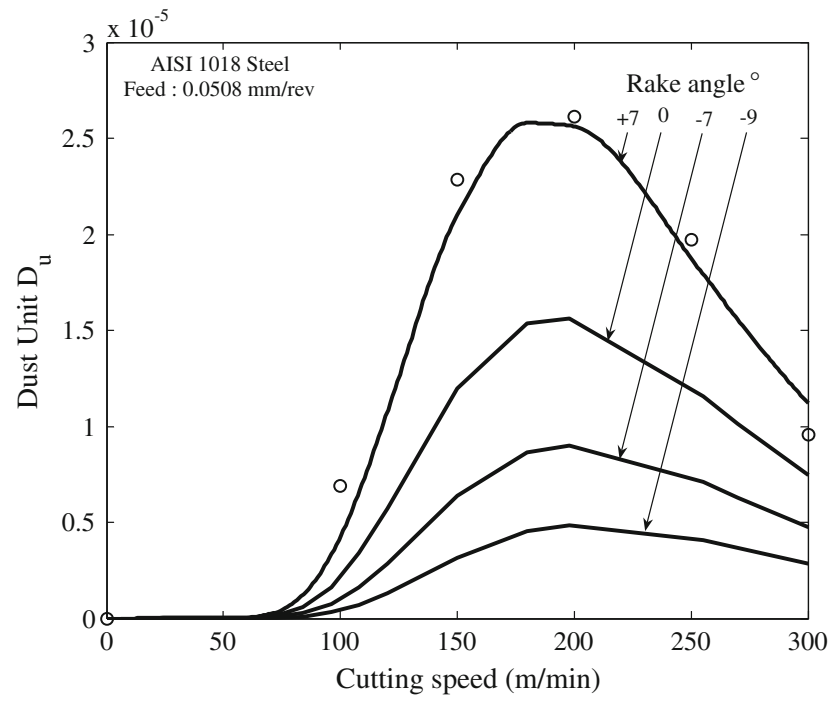

Fig. 11 Simulation results for dust emission varying on rake angle and cutting speed during dry machining of AISI 1018 steel

used in this model, which includes the effect of the workpiece material, the tool geometry, and the cutting parameters.

The influence of tool geometry, workpiece material, and cutting conditions on particle emission is significant. The new 


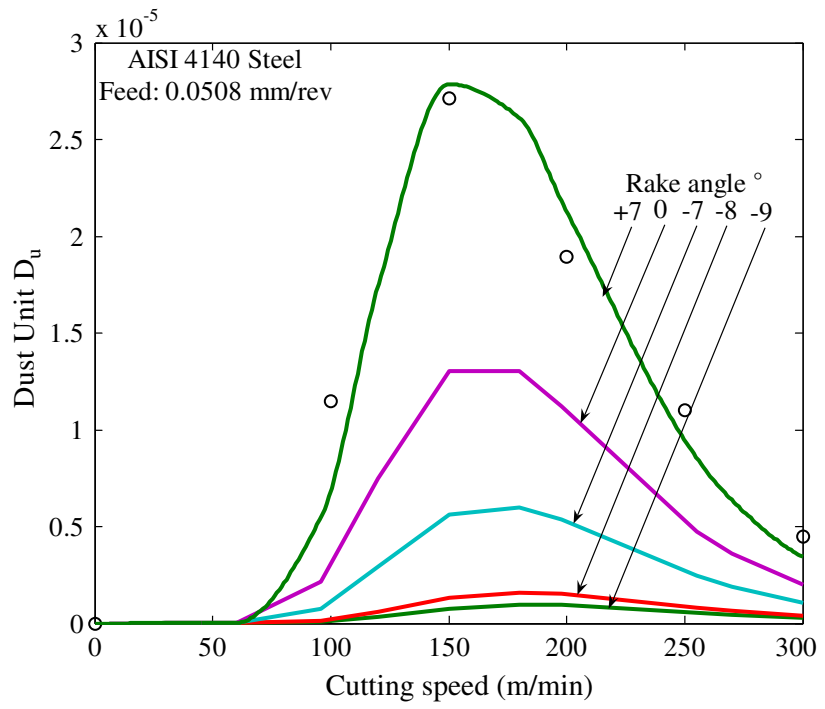

Fig. 12 Simulation results for dust emission varying on rake angle and cutting speed during dry machining of AISI 4140 steel

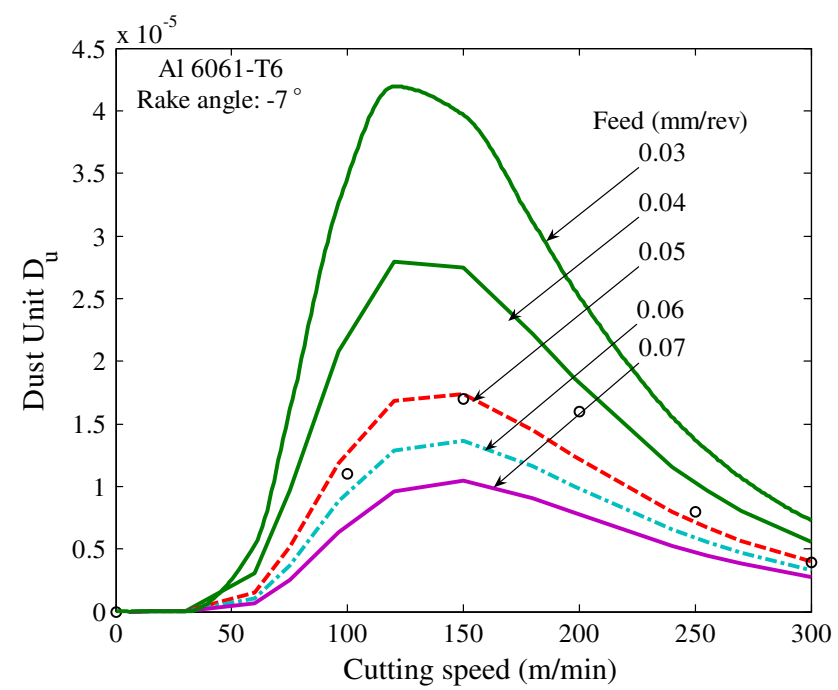

Fig. 13 Simulation results for dust emission varying on feed and cutting speed during dry machining of Al 6061-T6

relationship describing the particle emission is summarized by:

$$
\begin{aligned}
D_{\mathrm{u}}= & A \times \frac{\beta_{\max }-\beta}{\beta_{\mathrm{c}}} \times R_{a} \times \eta_{S} \cdot\left(\frac{V_{0}}{V}\right)^{\delta} \\
& \times \exp \left(\frac{-E_{\mathrm{A}}}{\tan \phi\left(1-C_{\mathrm{h}} \sin \alpha\right) V_{\mathrm{c}} \frac{F_{\mathrm{sh}}}{b f}}\right)
\end{aligned}
$$

where $D_{\mathrm{u}}$ is the dust unit, $\beta$ is the flow localization parameter defined by Xie et al. (Ref 42), $E_{\mathrm{A}}$ is the energy activation, $F_{\mathrm{Sh}}$ is the shear force, $V$ is the cutting speed, $f$ is the feed, $\phi$ is the shear angle, $\alpha$ is the tool rake angle, and finally, $\delta$ is a material parameter defined as

$$
\delta \equiv\left\{\begin{array}{l}
\delta \geq 1 \rightarrow \text { Ductile materials } \\
0.5<\delta<1 \rightarrow \text { Semi-ductile materials } \\
0<\delta \leq 0.5 \rightarrow \text { Britlle materials }
\end{array}\right.
$$

This $\delta$ parameter characterizes the effect of the material. Experiments confirm this description in the turning process for

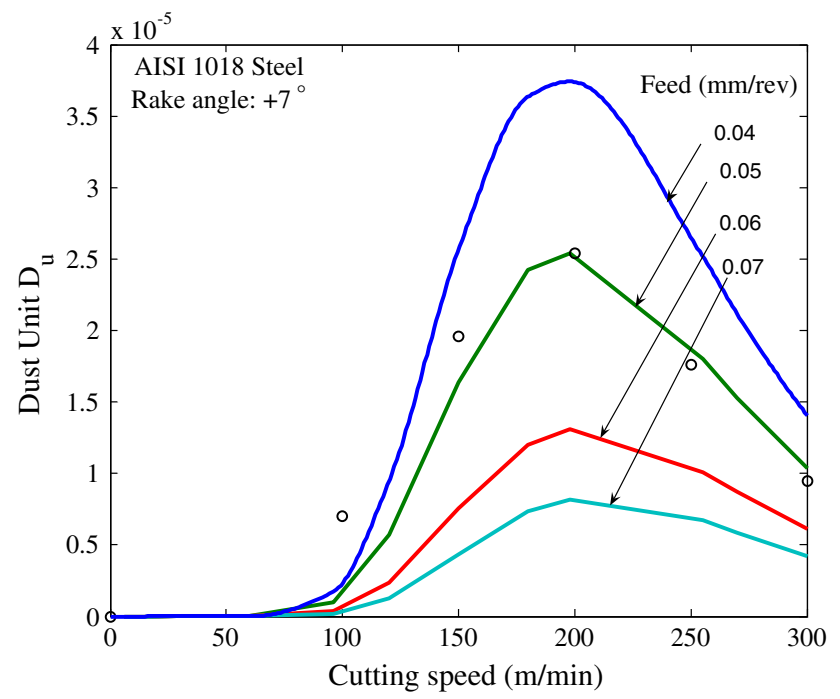

Fig. 14 Simulation results for dust emission varying on feed and cutting speed during dry machining AISI of 1018 steel

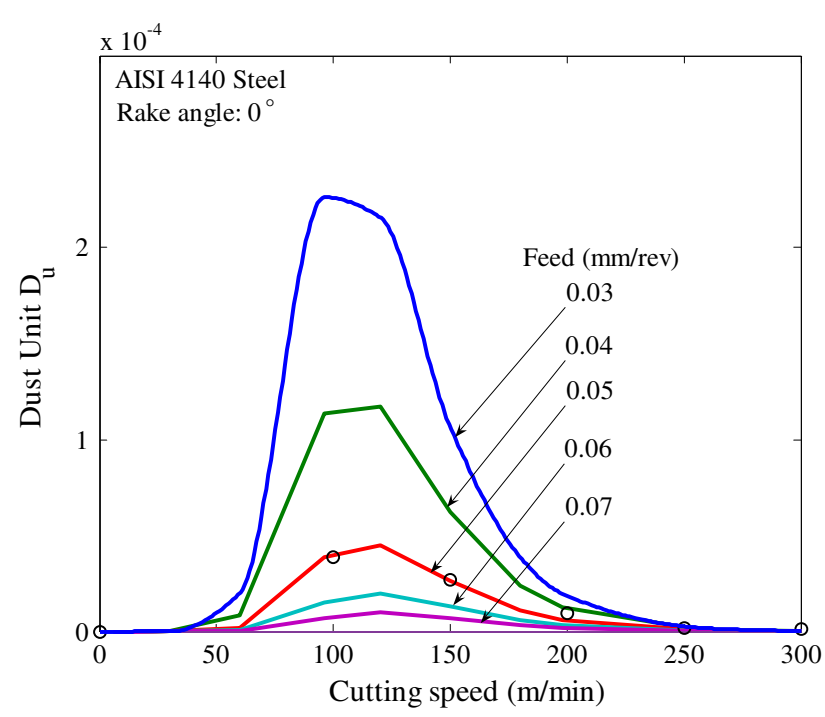

Fig. 15 Simulation results for dust emission varying on feed and cutting speed during dry machining of AISI 4140 steel

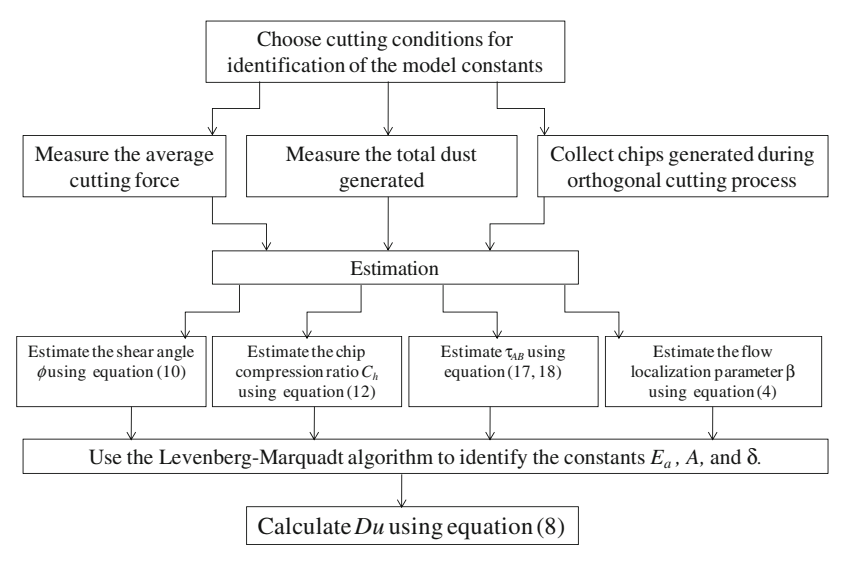

Fig. 16 Algorithm for the identification of the proposed model constants 


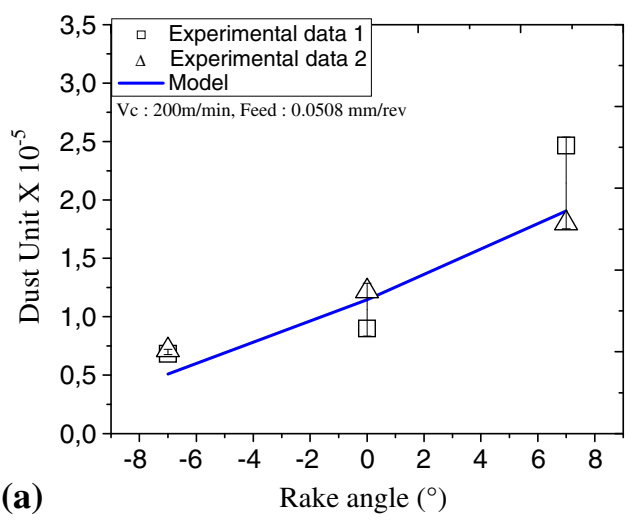

6061-T6 aluminum alloy

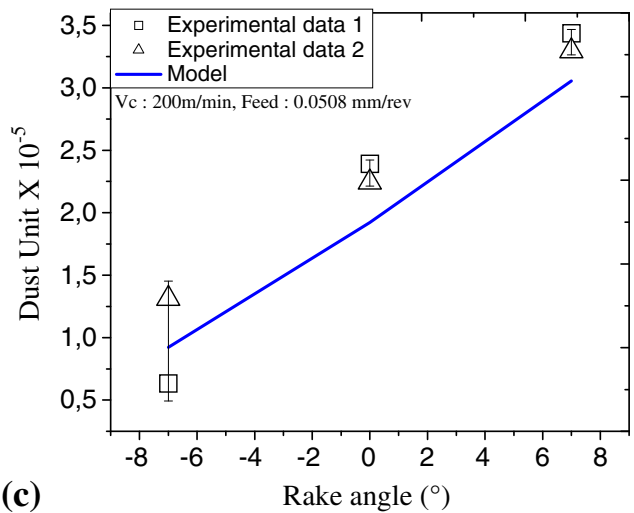

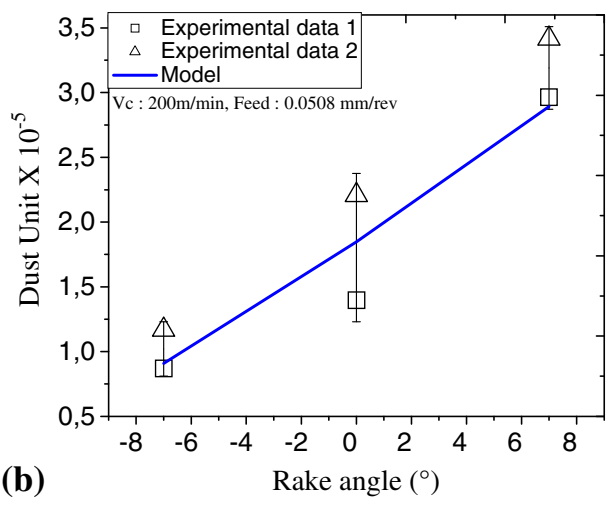

Grey Cast Iron

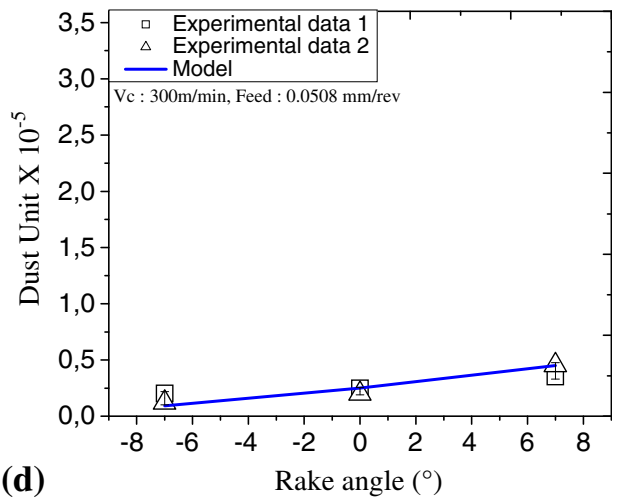

Fig. 17 Predicted dust emission data as given by Eq 8 (line) compared to two experimental data of AISI 1018, AISI 4140 steels, grey cast iron, and 6061-T6 aluminum alloy

Table 2 Model constants for orthogonal cutting of 6061-T6 aluminum alloy, 4140, and 1018 steels

\begin{tabular}{lcccccc}
\hline Material & $\boldsymbol{R}_{\mathbf{a}}, \boldsymbol{\mu \mathbf { m }}$ & $\boldsymbol{\delta}$ & $\boldsymbol{\beta}_{\mathbf{c}}$ & $\boldsymbol{\beta}_{\text {max }}$ & $\boldsymbol{A} \times \mathbf{1 0}^{\mathbf{- 4}}$ & $\boldsymbol{E}_{\mathbf{A}}, \mathbf{W} / \mathbf{m m}^{\mathbf{2}} \mathbf{s}$ \\
\hline 6061-T6 aluminum & 0.075 & 1.50 & 6.2 & 8.0 & 1.25 & 160 \\
4140 steel & 0.072 & 1.75 & 5.25 & & 2.50 & 250 \\
1018 steel & 0.073 & 2.10 & 5.12 & & 1.56 & 240 \\
\hline
\end{tabular}

different materials, different tool geometries, and for different cutting conditions. The generation of micronic and submicronic particles during an orthogonal cutting process is less pronounced when a negative tool rake angle is used than when a positive one is used. An increase in the feed rate also reduces the amount of particle emissions because the chip becomes segmented and brittle, which is why the model was proposed to enable us to predict and reduce particle emissions. The model is based on chip segmentation, tool rake face roughness, cutting parameters, workpiece material, and particle detachment energy. The chip segmentation parameter was developed based on analysis of chips collected during the experimentation on aluminum alloy 6061-T6, 1018, 4140 steels, and grey cast iron.

Simulation results and experimental results showed good agreement. The main advantage of this model is that it predicts particle emission based on cutting data, material properties, and tool geometry.

\section{Acknowledgments}

The authors thank Rio Tinto Alcan, the Natural Sciences and Engineering Research Council of Canada (NSERC), the Aluminum Research and Development Centre of Quebec (CQRDA), and the Aluminum Research Center (REGAL) for financial support.

\section{Appendix A: The proposed particle emission model solution algorithm}

The proposed particle emission model $D_{\mathrm{u}}$ (Eq 9) is a function of cutting conditions, work material properties, and tool geometry. It also includes the shear stress, the deformation, the shear force, and the variation of shear stress as a function of the temperature, all being variables which are not easy to determine. Zaghbani and Songmenehave proposed a predictive 
force temperature model and a solution algorithm for the high speed milling of ductile materials (Ref 43). This oblique cutting model is transformed into a predictive model and solution algorithm for orthogonal cutting. The variables are described, and then used to obtain the final equation for particle emission (Eq 9).

The analytical expressions for the shear strain and shear strain rate (Eq 15 and 17) in the primary shear zone are obtained from the modified Oxley shear plan theory developed by Tounsi (Ref 49).

Thermal and Mechanical Properties

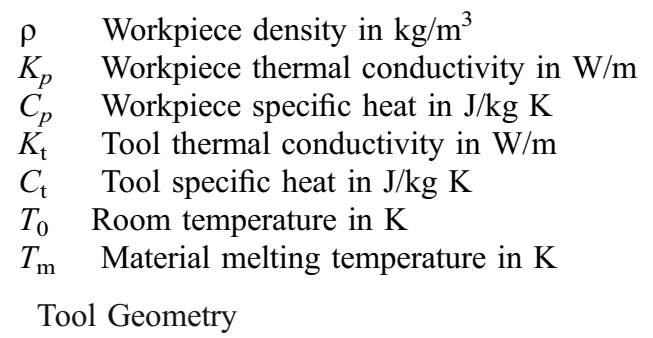

$\alpha \quad$ Rake angle

Cutting Parameters

$f \quad$ Feed in $\mathrm{mm} / \mathrm{rev}$

$b \quad$ Width of cut in $\mathrm{mm}$

$V_{\text {c }} \quad$ Cutting velocity in $\mathrm{m} / \mathrm{s}$

Needleman-Lemonds Constitutive Equation

$m_{1}, m_{2}$, and $n$

$\dot{\gamma}_{t}, \dot{\gamma}_{0}, \gamma_{0}$, and $\alpha_{\mathrm{NL}}$

\section{Variables}

$A \quad$ Zvoykin constant for the shear angle

$R_{\mathrm{a}} \quad$ Average roughness of the tool rake face

$V_{0} \quad$ Reference cutting velocity in $\mathrm{m} / \mathrm{s}$

$\beta_{\max } \quad$ Maximum segmentation coefficient

$\beta_{\mathrm{c}} \quad$ Segmentation coefficient

$E_{\mathrm{A}} \quad$ Particle activation energy

\section{Algorithm}

Calculate the shear angle $\phi$ using Zvorikyn formulae:

$\phi=A+\frac{\alpha-\lambda}{2}$

Calculate the contact length $C_{1}$

$C_{1}=\frac{h \sin \theta}{\sin \phi \cos (\theta+\alpha-\phi)}$

Calculate the ratio $C_{\mathrm{h}}$

$C_{\mathrm{h}}=\frac{\sin \phi}{\cos (\phi-\alpha)}$

Calculate the segmentation density $\eta_{\mathrm{S}}$

$\eta_{\mathrm{S}}=\frac{1}{C_{1}}$

Calculate the average shear strain in the Primary Shear Zone

$\bar{\gamma}_{\mathrm{AB}}=\frac{\cos \alpha}{\cos (\phi-\alpha) \sin \phi}$
Calculate the coefficient $B_{0}$

$B_{0}=\sqrt{\frac{K_{p} \gamma_{\mathrm{AB}}}{V f}}$

Calculate the shear rate in the Primary Shear Zone

$\dot{\bar{\gamma}}_{\mathrm{AB}}=\frac{2 V \cos \alpha}{e_{\mathrm{psz}} \cos (\phi-\alpha)}$

If $\dot{\bar{\gamma}}_{\mathrm{AB}} \leq \dot{\bar{\gamma}}_{\mathrm{t}}$, then

Solve this equation:

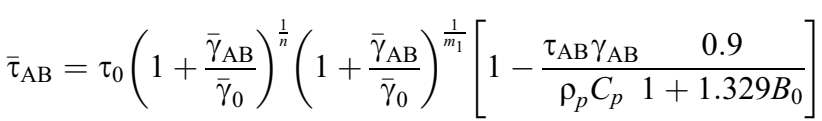

Get shear stress in the Primary Shear Zone $\tau_{\mathrm{AB}}$

Else solve this equation:

$$
\begin{aligned}
\bar{\tau}_{\mathrm{AB}}= & \tau_{0}\left(1+\frac{\bar{\gamma}_{\mathrm{AB}}}{\bar{\gamma}_{0}}\right)^{\frac{1}{n}}\left(1+\frac{\bar{\gamma}_{\mathrm{AB}}}{\bar{\gamma}_{0}}\right)^{\frac{1}{m_{1}}} \\
& \times\left[1-\frac{\tau_{\mathrm{AB}} \gamma_{\mathrm{AB}}}{\rho_{p} C_{p}} \frac{0.9}{1+1.329 B_{0}}\right]\left(1-\frac{\bar{\gamma}_{\mathrm{t}}}{\bar{\gamma}_{0}}\right)^{\frac{1}{m_{1}}-\frac{1}{m_{2}}}
\end{aligned}
$$

Get the shear stress in the Primary Shear Zone $\tau_{\mathrm{AB}}$

Calculate the temperature in the Primary Shear Zone $T_{\mathrm{AB}}$

$T_{\mathrm{AB}}=T_{0}+\frac{\tau_{\mathrm{AB}} \gamma_{\mathrm{AB}} 0.9}{\rho_{p} C_{p} 1+1.329 B_{0}}$

Calculate the shearing force $F_{\text {sh }}$

$F_{\mathrm{sh}}=\frac{\tau_{\mathrm{AB}} f b}{\sin \phi}$

Calculate the chip segmentation coefficient $\beta$ using Xie formulae (Ref 42):

$\beta=-\frac{\sqrt{3}}{m}\left[\mu+\frac{0.9(\partial \tau / \partial T)}{\rho_{p} C_{p}\left(1+1.328 B_{0}\right)}\right]\left[\mu \gamma+1-\frac{0.664 B_{0}}{1+1.328 B_{0}}\right]$

Calculate the dust unit $D_{\mathrm{u}}$ using Eq 9.

\section{Appendix B: The Flow Localization Parameter $\beta$}

The proposed flow localization parameter $\beta$ of the model (Eq 4) developed by Xie et al. (Ref 42) is a function of the cutting conditions, work material properties, and tool geometry.

Thermal and Mechanical Properties

$\mu$ Strain hardening parameter

$m$ Strain rate sensitivity

\section{Algorithm}

Calculate the average shear strain in the Primary Shear Zone (Eq 15)

Calculate the coefficient $B_{0}$ (Eq 16)

Calculate the shear rate in the Primary Shear Zone (Eq 17) 
Calculate the Needleman-Lemonds constitutive equation:

$$
\left\{\begin{array}{l}
\left(1+\frac{\dot{\bar{\gamma}}_{\mathrm{AB}}}{\bar{\gamma}_{0}}\right)=\left(\frac{\bar{\tau}_{\mathrm{AB}}}{g\left(\bar{\tau}_{\mathrm{AB}}\right)}\right)^{m_{1}} \rightarrow \dot{\bar{\gamma}}_{\mathrm{AB}} \leq \dot{\bar{\gamma}}_{\mathrm{t}} \\
\left(1+\frac{\dot{\bar{\gamma}}_{\mathrm{AB}}}{\bar{\gamma}_{0}}\right)\left(1+\frac{\dot{\bar{\gamma}}_{\mathrm{t}}}{\bar{\gamma}_{0}}\right)^{\frac{m_{2}}{m_{1}}-1}=\left(\frac{\bar{\tau}_{\mathrm{AB}}}{g\left(\bar{\tau}_{\mathrm{AB}}\right)}\right)^{m_{2}} \rightarrow \dot{\bar{\gamma}}_{\mathrm{AB}} \geq \dot{\bar{\gamma}}_{\mathrm{t}} \\
g\left(\bar{\tau}_{\mathrm{AB}}\right)=\tau_{0}\left(1+\frac{\bar{\gamma}_{\mathrm{AB}}}{\bar{\gamma}_{0}}\right)^{\frac{1}{n}}\left[1-\alpha_{\mathrm{NL}}\left(T-T_{0}\right)\right]
\end{array}\right.
$$

where $n$ is the hardening coefficient, $\alpha_{\mathrm{NL}}$ is the coefficient for thermal softening, $\tau_{0}$ is the elastic average shear stress, $\bar{\tau}$ is the average shear stress, $\dot{\bar{\gamma}}_{\mathrm{t}}$ is the transition shear strain rate, $m_{1}$ and $m_{2}$ are the coefficients of sensitivity to the strain rate in the low and high regimes, respectively, and $\dot{\bar{\gamma}}_{0}$ is the reference shear strain rate.

The shear stress in the Primary Shear Zone will be

$\bar{\tau}_{\mathrm{AB}}=\left\{\begin{aligned} \tau_{0} & \left(1+\frac{\bar{\gamma}_{\mathrm{AB}}}{\bar{\gamma}_{0}}\right)^{\frac{1}{n}}\left(1+\frac{\dot{\bar{\gamma}}_{\mathrm{AB}}}{\bar{\gamma}_{0}}\right)^{\frac{1}{m_{1}}}\left[1-\alpha_{\mathrm{NL}}\left(T-T_{0}\right)\right] \\ & \rightarrow \dot{\bar{\gamma}}_{\mathrm{AB}} \leq \dot{\bar{\gamma}}_{\mathrm{t}} \\ \tau_{0} & \left(1+\frac{\bar{\gamma}_{\mathrm{AB}}}{\bar{\gamma}_{0}}\right)^{\frac{1}{n}}\left(1+\frac{\dot{\bar{\gamma}}_{\mathrm{AB}}}{\bar{\gamma}_{0}}\right)^{\frac{1}{m_{2}}}\left(1+\frac{\dot{\bar{\gamma}}_{\mathrm{t}}}{\bar{\gamma}_{0}}\right)^{\frac{1}{m_{1}}-\frac{1}{m_{2}}} \\ & \times\left[1-\alpha_{\mathrm{NL}}\left(T-T_{0}\right)\right] \rightarrow \dot{\bar{\gamma}}_{\mathrm{AB}} \geq \dot{\bar{\gamma}}_{\mathrm{t}}\end{aligned}\right.$

If $\dot{\bar{\gamma}}_{\mathrm{AB}} \leq \dot{\bar{\gamma}}_{\mathrm{t}}$, then

Calculate the variation of shear stress in the Primary Shear Zone as

$\frac{\partial \bar{\tau}_{\mathrm{AB}}}{\partial T}=\tau_{0}\left(1+\frac{\bar{\gamma}_{\mathrm{AB}}}{\bar{\gamma}_{0}}\right)^{\frac{1}{n}}\left(1+\frac{\dot{\bar{\gamma}}_{\mathrm{AB}}}{\bar{\gamma}_{0}}\right)^{\frac{1}{m_{1}}}\left[-\alpha_{\mathrm{NL}}\right]$

Get the shear stress in the Primary Shear Zone $\tau_{\mathrm{AB}}$

Else Calculate the variation of shear stress in the Primary Shear Zone as

$$
\frac{\partial \bar{\tau}_{\mathrm{AB}}}{\partial T}=\tau_{0}\left(1+\frac{\bar{\gamma}_{\mathrm{AB}}}{\bar{\gamma}_{0}}\right)^{\frac{1}{n}}\left(1+\frac{\dot{\bar{\gamma}}_{\mathrm{AB}}}{\bar{\gamma}_{0}}\right)^{\frac{1}{m_{2}}}\left(1+\frac{\dot{\bar{\gamma}}_{\mathrm{t}}}{\bar{\gamma}_{0}}\right)^{\left(\frac{1}{m_{1}}-\frac{1}{m_{2}}\right)}\left[-\alpha_{\mathrm{NL}}\right]
$$

Get the shear stress in the Primary Shear Zone $\tau_{\mathrm{AB}}$

Calculate the chip segmentation coefficient $\beta$ using Xie (Ref 42) formulae (Eq 22).

\section{References}

1. F.P. Holt, Inhaled Dust and Disease, Wiley-Interscience/John Wiley, New York, 1987

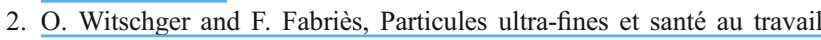
1-caractéristiques et effets potentiels sur la santé, INRS, Vol 199, 2005, p 21-35. http://www.inrs.fr/htm/particules ultra-fines sante travail.html (in French)

3. C. Ostiguy, G. Lapointe, L. Ménard, Y. Cloutier, M. Trottier, M. Boutin, M. Antoun, and C. Normand, Les nanoparticules: État des connaissances sur les risques en santé et sécurité du travail, IRSST, 2006. http://www.irsst.qc.ca/files/documents/PubIRSST/R-455.pdf (in French)

4. Q. Zhang, Y. Kusaka, and K. Donaldson, Comparative Pulmonary Responses Caused by Exposure to Standard Cobalt and Ultra Fine Cobalt, J. Occup. Health, 2000, 42, p 179-184

5. G. Oberdörster, E. Oberdörster, and J. Oberdörster, Nanotechnology: An Emerging Discipline Evolving from Studies of Ultra Fine Particles, Environ. Health Perspect., 2005, 113(7), p 823-839
6. G. Kreyling, M. Semmler, F. Erbe, P. Mayer, S. Takenaka, H. Schultz, G. Oberdoster, and A. Ziesenis, Translocation of Ultra Fine Insoluble Iridium Particles from Lungs Epithelium to Extra Pulmonary Organs, J. Toxicol. Environ. Health, 2002, 65(20), p 1513-1530

7. C. Katz, A. Burkhalter, and W. Dreyer, Fluorescent Latex Micro Spheres as a Retrograde Neuronal Marker for In Vivo and In Vitro Studies of Visual Cortex, Nature, 1984, 310, p 498-500

8. A.C. Elder, R. Gelein, M. Azadniv, M. Frampton, J. Finkelstein, and G. Oberdorster, Systemic Effects of Inhaled Ultra Fine Particles in Two Compromised, Aged Rat Strains. Inhale Toxicol., 2004, 16, p 461-471

9. M. Ramulu, P. Young, and H. Kao, Drilling of Graphite/Bismaleimide Composite Material, J. Mater. Eng. Perform., 1999, 8, p 330-338

10. Y. Kimura and J. Sugimura, Micro Geometry of Sliding Surfaces and Wear Particles, Wear, 1984, 100, p 33-45

11. Y. Zhu and H.A. Kishawy, Influence of Alumina Particles on the Mechanics of Machining Metal Matrix Composites, Int. J. Mach. Tools Manuf., 2005, 45, p 389-398

12. M. Nouari and I. Iordanoff, Effect of the Third-Body Particles on the Tool-Chip Contact and Tool-Wear Behaviour During Dry Cutting of Aeronautical Titanium Alloys, Tribol. Int., 2007, 40, p 1351-1359

13. M. Cocks, Interaction of Sliding Metal Surfaces, J. Appl. Phys., 1962, 33(7), p 2152-2161

14. D.H. Hwang, D.E. Kim, and S.J. Le, Influence of Wear Particle Interaction in the Sliding Interface on Friction of Metals, Wear, 1999, 225-229(1), p 427-439

15. P.A. Swanson and A.F. Vetter, The Measurement of Abrasive Particle Shape and Its Effect on Wear, ASLE Trans., 1984, 28, p 225-230

16. S. Bahadur and R. Badruddin, Erodent Particle Characterization and the Effect of Particle Size and Shape on Erosion, Wear, 1990, 138, p 189-208

17. M. Liebhard and A. Levy, The Effect of Erodent Particle Characteristics on the Erosion of Metals, Wear, 1991, 151, p 381-390

18. G.B. Stachowiak and G.W. Stachowiak, The Effects of Particle Characteristics on Three-Body Abrasive Wear, Wear, 2001, 249, p 201-207

19. WHO, Hazard Prevention and Control in the Work Environment: Airborne Particle, Prevention and Control Exchange (PACE), World Health Organization, WHO/SDE/OEH/99.14, Geneva, Switzerland, 1999, p 1-219

20. H. Tönshoff, B. Karpuschewski, and T. Glatzel, Particle Emission and Emission in Dry Grinding, Ann. CIRP, 1997, 46(2), p 693-695

21. V. Songmene, B. Balout, and J. Masounave, Clean Machining: Experimental Investigation on Particle Formation, Part II: Influence of Machining Strategies and Drill Condition, Int. J. Environ. Conscious Des. Manuf. (ECDM), 2008, 14(1), p 17-33

22. H.W. Rossmoore and L.A. Rossmoore, Effect of Microbial Growth Products on Biocide Activity in Metalworking Fluids, Symposium on Extra cellular Microbial Products in Bio-Deterioration, Vol 27(2), Apr 9-10, 1990, International Bio-deterioration, 1990, p 145-156

23. M. Sondossi, H.W. Rossmoore et al., Relative Formaldehyde Resistance Among Bacterial Survivors of Biocide-Treated Metalworking Fluid, Int. Biodeter. Biodegr., 2001, 48(1-4), p 286-300

24. D.K. Verma, D.S. Shaw, et al., An Evaluation of Analytical Methods, Air Sampling Techniques, and Airborne Occupational Exposure of MetalWorking Fluids, J. Occup. Environ. Hyg., 2006, 3, p 53-66

25. NOSH: National Institute for Occupational Safety and Health, Criteria for a Recommended Standard: Occupational Exposure to Metalworking Fluids, DHHS Pub. No. 98-102, NIOSH, Cincinnati, Ohio, 1998

26. J.W. Sutherland, V.N. Kulur et al., Experimental Investigation of Air Quality in Wet and Dry Turning, CIRP Ann.-Manuf. Technol., 2000, 49(1), p 61-64

27. I. Zaghbani, V. Songmene, and R. Khettabi, Fine and Ultra Fine Particle Characterisation and Modeling In High Speed Milling of 6061T6 Aluminium Alloy, J. Mater. Eng. Perform., 2008, ASM International. doi:10.1007/s11665-008-9265-x

28. B. Balout, V. Songmene, and J. Masounave, An Experimental Study of Particle Generation During Dry Drilling of Pre-Cooled and Pre-Heated Workpiece Materials, J. Manuf. Process., 2007, 9(1), p 23-34

29. V. Songmene, B. Balout, and J. Masounave, Clean Machining: Experimental Investigation on Particle Formation Part I: Influence of Machining Parameters and Chip Formation, Int. J. Environ. Conscious Des. Manuf. (ECDM), 2008, 14(1), p 1-16 
30. R. Khettabi, V. Songmene, and J. Masounave, Effect of Tool Lead Angle and Chip Formation Mode on Particle Emission in Dry Cutting, J. Mater. Process. Technol., 2007, 194(1-3), p 100-109

31. R. Khettabi, V. Songmene, and J. Masounave, Effects of Speeds, Materials and Tool Rake Angles on Metallic Particle Emission During Orthogonal Cutting, J. Mater. Eng. Perform., 2009, Accepted for Publication

32. J.R.K. Zipf and Z.T. Bieniawski, A Fundamental Study of Respirable Particle Generation in Coal, Min. Sci. Technol., 1989, 9(1), p 87-99

33. S.J. Page and J.A. Organiscak, Semi-Empirical Model for Predicting Surface Coal Mine Drill Respirable Particle Emission, Int. J. Surf. Min. Reclam. Environ., 2004, 18(1), p 42-59

34. D. Chen, M. Sarumi, and S.T.S. Al-Hassani, Computational Mean Particle Erosion Model, Wear, 1998, 214, p 64-73

35. Z. Zhang, L. Zhang, and Y.-W. Mai, Modelling Friction and Wear of Scratching Ceramic Particle-Reinforced Metal Composites, Wear, 1994, 176, p 231-237

36. E. Rabinowicz, Shape of Adhesive Wear Particles, ASME, New York, NY, USA, 1985, p 1377-1386

37. P.L. Ko, S.S. Iyer, H. Vaughan, and M. Gadala, Finite element Modelling of Crack Growth and Wear Particle Formation in Sliding Contact, Wear, 2001, 250-251, p 1265-1278

38. S.S. Akarca, W.J. Altenhof, and A.T. Alpas, Characterization and Modeling of Subsurface Damage in a 356 Aluminum Alloy Subjected to Multiple Asperity Sliding Contacts, Minerals, Metals and Materials Society, Warrendale, PA, USA, 2005, p 107-120

39. H.-W. Fang, Characteristic Modeling of the Wear Particle Formation Process from a Tribological Testing of Polyethylene with Controlled Surface Asperities, J. Appl. Polym. Sci., 2007, 103, p 587-594

40. H.-W. Fang, et al., Preparation of UHMWPE Particles and Establishment of Inverted Macrophage Cell Model to Investigate Wear Particles
Induced Bioactivities, J. Biochem. Biophys. Methods, 2006, 68, p 175187

41. S. Rautio, P. Hynynen, I. Welling, I. Hemmil, P. Usenius, and A. Narhi, Modelling of Airborne Particle Emissions in CNC MDF Milling, Holz als Roh- und Werkstoff, 2007, 65(7), p 335-341

42. J.Q. Xie, A.E. Bayoumi, and H.M. Zbib, Study on Shear Banding in Chip Formation of Orthogonal Machining, Int. J. Mach. Tools Manuf., 1996, 36(7), p 835-847

43. I. Zaghbani and V. Songmene, A Force-Temperature Model Including a Constitutive Equation for Dry and High Speed Milling of Aluminum Alloys, J. Mater. Process. Technol., 2008, doi:10.1016/j.jmatprotec. 2008.05.050

44. P.U. Arumugam, A.P. Malshe, S.A. Batzer, and D.G. Bhat, Study of Airborne Particle Emission and Process Performance During Dry Machining of Aluminum-Silicon Alloy with PCD and CVD Diamond Coated Tools NAMRC, May 21-24, 2002 (West Lafayette, ID), Society of Manufacturing Eng., MR02-153, 2002, p 1-8

45. J. Palmqvist and S. Gustafsson, Emission of Particle in Planning and Milling of Wood, Holz Roh-Werkst, 1999, 57, p 164-170

46. P.U. Arumugam, A.P. Malshe, and S.A. Batzer, Dry Machining of Aluminium-Silicon Alloy Using Polished CVD Diamond-Coated Cutting Tools Inserts, Surf. Coat. Technol., 2006, 200(11), p 3399-3403

47. P. Atkins and J. de Paula, Physical Chemistry, 8th ed., W. H. Freeman and Company, New York, 2006

48. J. Masounave, Y. Jallais, and J.-M. Welter, Effect of Temperature on the Drilling of Brass and Aluminum, Matériaux Tech., 2007, 95, p 331-342

49. N. Tounsi, Analytical and Numerical Investigation of the Strain Rate Field in the Secondary Shear Zone, 2005 ASME International Mechanical Engineering Congress and Exposition, Orlando, Florida, USA, 2005 